ISSN: 0213-2052 - eISSN: 2530-4100

DOI: https://doi.org/10.14201/shha202139279308

\title{
UN ESTUDIO DE LAS RELACIONES SOCIALES DE LOS SOLDADOS AUXILIARES EN HISPANIA. LAS FUENTES EPIGRÁFICAS*
}

\section{Social relationships of Roman auxiliary soldiers in Hispania through epigraphy}

\section{Roberto LÓPEZ CASADO}

Profesor de Geografía e Historia del IES Sierra del Valle (La Adrada, Ávila) rolopez14@gmail.com

Fecha de recepción: 14-2-2021 Fecha de aceptación: 6-05-2021

ORCID: https://orcid.org/0000-0002-3838-8819

RESUMEN: Analizamos, desde una perspectiva epigráfica, las relaciones sociales que mantuvieron los soldados auxiliares del ejército romano en Hispania. Las inscripciones reflejan un predominio de los núcleos familiares, con una significativa escasa presencia de la esposa o concubina, al contrario de lo que sucede en otros cuerpos del ejército romano.

Palabras clave: epigrafía; ejército romano; unidades auxiliares; relaciones sociales; Hispania.

ABSTRACT: In the following paper we study, from a epigraphic point of view, the social relationships of Roman auxiliary soldiers in Hispania. Inscriptions reflect a predominance of the kinship, with a significant low presence of the wife, unlike what we see in other branches of the Roman army.

Keywords: epigraphy; Roman army; auxiliary units; social relationships; Hispania.

* Quiero expresar mi gratitud a los profesores José D'Encarnação (Universidade de Coimbra) y José María Vallejo (Universidad del País Vasco) por sus comentarios. Los errores son exclusivamente míos. 


\section{INTRODUCCIÓN}

Iban al frente cuatro águilas legionarias y a los lados otros tantos estandartes de otras legiones; luego las enseñas de doce escuadrones de caballería, y, tras las formaciones de a pie, los de a caballo; después treinta y cuatro cohortes, separadas según fueran su nacionalidad y su tipo de armamento $^{1}$.

En este pasaje de las Historias, Tácito nos describe la entrada triunfal de Vitelio en Roma. En él apreciamos la inferior categoría que tenían las unidades auxiliares en el seno del ejército romano ${ }^{2}$. Esta distinción se basaba en una diferencia jurídica, ya que los soldados auxiliares eran reclutados entre los peregrini, mientras que las legiones estaban formadas por ciudadanos romanos. En este sentido, las vidas de los soldados que eran ciudadanos romanos eran más «valiosas». Esto mismo nos lo reveló Tácito, cuando detalla la disposición del ejército romano dirigido por su suegro Agrícola en la batalla del Mons Graupius contra las tribus caledonias lideradas por Calgacus.

Mientras hablaba Agrícola crecía el ardor de los soldados y una gran explosión de entusiasmo acompañó el final de su arenga. Al punto corrieron hacia las armas. Enardecidos como estaban y prontos a precipitarse contra el enemigo, los dispuso de forma que las tropas auxiliares de infantería, ocho mil hombres, formasen en el centro, y los tres mil jinetes se desplegasen en las alas. Las legiones se situaron delante de la empalizada, lo que supondría un honor en caso de victoria, al conseguirse sin sangre romana, y una ayuda si eran rechazadas las fuerzas de delante ${ }^{3}$.

1. Tac. Hist., II, 89, 1. Quattuor legionum aquilae per frontem totidemque circa e legionibus aliis vexilla, mox duodecim alarum signa et post peditum ordines eques; dein quattuor et triginta cohortes, ut nomina gentium aut species armorum forent, discretae. Traducción de J. L. Moralejo. Akal, 1990.

2. Estas unidades han sido objeto de estudios monográficos (C. Cichorius -artículos dentro de la enciclopedia comúnmente llamada Pauly-Wissowa-, G. Cheesman, P. Holder, D. Saddington o J. Spaul). Más recientemente se han publicado dos obras consecuencia de sendos congresos sobre las tropas auxiliares (Wolff y Faure, Les auxiliaires y n. ${ }^{\circ}$ 6-2017 de la revista internacional $H i M A$ ).

3. Tac., Agr., 35, 2. Et adloquente adbuc Agricola militum ardor eminebat, et finem orationis ingens alacritas consecuta est, statimque ad arma discursum. Instinctos ruentisque ita disposuit, ut peditum auxilia, quae octo milium erant, mediam aciem firmarent, equitum tria milia cornibus adfunderentur. Legiones pro vallo stetere, ingens victoriae decus citra Romanum sanguinem bellandi, et auxilium, si pellerentur. Traducción de J. M. Requejo. Gredos, 1981. 
En este fragmento Tácito no solo evidencia esa menor consideración hacia los auxilia, sino también el modo de empleo de estas unidades, que van a pasar de realizar funciones de apoyo a las legiones a luchar en primera línea de batalla ${ }^{4}$.

Roma reclutó en torno a dos millones de soldados auxiliares desde Augusto hasta Alejandro Severo, documentándose casi 400 destacamentos entre alas y cohortes 5 . Estos cuerpos militares eran reclutados en los territorios recientemente conquistados entre individuos que no poseían la ciudadanía romana, aunque con el tiempo los ciudadanos romanos se enrolarán en estas unidades, bien porque no cumplían con los requisitos para entrar en las legiones, bien por su demostrada habilidad y coraje en determinados cuerpos militares o por el lugar de acuartelamiento de la unidad en concreto $^{6}$. La principal zona de reclutamiento a nivel imperial fue Europa, de donde salió el $78,5 \%$ de los auxilia 7 . Sin el apoyo de las unidades auxiliares, Roma no hubiera podido oponer un frente de batalla en todas sus fronteras. Asimismo, los podemos considerar como un instrumento y un producto del imperialismo romano ${ }^{8}$.

Los auxilia, como fuerzas mercenarias especialistas que luchaban al lado de las legiones, aparecieron a finales del siglo III a. C., cuando las conquistas se realizaron fuera de la península itálica ${ }^{9}$. No obstante, corresponde a Augusto la organización de los destacamentos auxiliares integrados en el ejército romano ${ }^{10}$; y a Claudio una homogeneización en el mando, situando al frente de estas unidades a miembros del ordo equester, constituyendo una verdadera militia equestris ${ }^{11}$. Estos soldados van a percibir una menor remuneración que los legionarios, los pretorianos y los urbaniciani ${ }^{12}$. En cuanto a la duración del oficio de las armas, este se podía prolongar hasta los 30 años bajo la dinastía julio-claudia ${ }^{13}$. No será hasta la época flavia cuando se regularice la duración del servicio militar,

4. Holder, Studies in the Auxilia, 140; Le Bohec, "Sur les auxiliaires", 30.

5. Haynes, Blood of the Provinces, 4 y 103.

6. Holder, Studies in the Auxilia, 50.

7. Le Bohec, El ejército romano, 130. La parte occidental aportó el 56\% de los hombres.

8. Haynes, Blood of the Provinces, 4.

9. Brizzi, "Socii et auxilia", 49.

10. Cheesman, The Auxilia, 133; Webster, The Roman Imperial Army, 144; Holder, Studies in the Auxilia, 5; Meyer, The creation, 60; Le Bohec, «Sur les auxiliaires», 27; Speidel, "Actium, Allies", 80.

11. Holder, Studies in the Auxilia, 75-77.

12. Speidel, "Roman army pay scales", 56. Salvo los equites alares, que recibirían el mismo salario que sus homólogos legionarios.

13. CIL, XIII, 1041. 
fijándose en torno a los 25 años ${ }^{14}$. Una vez obtenida la licencia, el soldado auxiliar recibía una serie de privilegios para iniciar su vida como veterano y poder reinsertarse en la sociedad civil. Entre estas prerrogativas se encontraban la ciudadanía romana o el ius connubii, reflejadas todas ellas en los diplomas militares ${ }^{15}$. Cabe aquí citar a Le Bohec cuando expresó que eel servicio militar funciona como una máquina de difusión de la ciudadanía ". Parece ser que los auxilia no recibían los praemia militiae tras la missio, es decir, una cantidad de dinero o tierras ${ }^{17}$. No obstante, en el siglo III, las fuentes mencionan repartos de tierras para los soldados veteranos sin especificar la rama del ejército de la que procedían. Sin embargo, hay que tener en cuenta que en esta fecha la distinción entre auxiliares y legionarios no sería tan acusada debido a la Constitutio Antoniniana ${ }^{18}$.

Si nos centramos en Hispania ${ }^{19}$, el territorio de estudio de este trabajo, los problemas a la hora de conocer el despliegue de las unidades auxiliares son verdaderamente significativos debidos a la exigua documentación y a su difícil interpretación; a esto se suma la mayor movilidad de estos destacamentos entre diferentes provincias ${ }^{20}$. Otra de las dificultades que encontramos en este estudio es identificar como soldado perteneciente a los auxilia a aquellos militares cuya inscripción no indica la unidad a la que estaban adscritos, puesto que tan solo aparece en el campo epigráfico miles, eques o veteranus. Para dilucidar esta cuestión debemos prestar atención a otros factores como la onomástica, la origo o, en ocasiones, el lugar de hallazgo. No obstante, no siempre tenemos la absoluta certeza a la hora de atribuir un soldado a un cuerpo auxiliar, como veremos más adelante. A pesar de todo, nuestro objetivo es analizar la sociabilidad de los milites auxiliares utilizando las fuentes epigráficas.

14. Holder, Studies in the Auxilia, 47-48.

15. Perea Yébenes, "Los diplomas militares», 104. Estos documentos se convierten en el salvoconducto del soldado para demostrar la legitimidad de su unión y de su descendencia — sus hijos serían ciudadanos romanos como él- Sin embargo, en torno al año 140 se produjo una transformación en la fórmula de los diplomas. La expresión ipsis liberis posterisque fue suprimida, privando de la ciudadanía a los hijos de los soldados auxiliares nacidos durante el servicio militar (Waebens, «Imperial policy», 5; Eck, "Der Einschluss», 68).

16. Le Bohec, El ejército romano, 134.

17. Watson, The Roman Soldier, 148-149; Haynes, Blood of the Provinces, 347-350. Esta es la posición mayoritaria respecto a este tema. No obstante, en ambas citas hallamos referencias a este debate historiográfico, donde otros especialistas se postulan a favor de la concesión de los praemia militiae a los soldados auxiliares.

18. Haynes, Blood of the Provinces, 348.

19. Un estado de la cuestión sobre las tropas auxiliares en Hispania se encuentra en Palao Vicente, «Las tropas auxiliares».

20. Palao Vicente, «Las tropas auxiliares», 171-173. 


\section{LAS RELACIONES SOCIALES DE LOS SOLDADOS AUXILIARES EN ACTIVO ${ }^{21}$}

Antes de nada, hay que tener en cuenta las motivaciones para erigir un monumento epigráfico. La principal es la herencia, que recaía generalmente en un miembro de la familia, aunque por testamento se podía nombrar heredero (heres) a una persona ajena a la parentela. El heredero contraía un deber legal y moral para con el finado, al que debía conmemorar. No obstante, si el motivo no era la herencia, la conmemoración se podía realizar por afecto o para honrar la memoria del difunto ${ }^{22}$. En la práctica, la herencia y el afecto eran motivaciones que se entremezclaban a la hora de erigir un monumento epigráfico. Por ello, 18 de los 22 epígrafes recogidos en el corpus de trabajo son inscripciones de tipología funeraria ${ }^{23}$.

La familia, entendida como el parentesco ascendente, colateral y la cónyuge, es la que más inscripciones dedica. Los soldados conmemorados por los núcleos familiares eran todos hispanos. Los progenitores aparecen en cuatro monumentos epigráficos, si bien solamente fueron dedicantes de dos. Por un lado, Lapoena Annonis f. conmemoró a su hijo, un signifer

21. Destacamos aquí dos inscripciones que presentan una incertidumbre en cuanto a la adscripción de los soldados a unidades auxiliares. El eques L. Sempronius [---] (HEp, 20, $2011,40)$ ha sido considerado como un soldado asignado a una unidad auxiliar, aunque sin poder precisar cuál (Perea Yébenes, «Notas», 204-206). La ruptura del monumento epigráfico ha impedido corroborar esta hipótesis. En Clunia, el lugar de hallazgo del monumentum, se documentó en un testimonio epigráfico el ala Augusta (CIL, II, 5792). No obstante, en esta zona también se han hallado inscripciones de soldados que servían en las legiones. Más al norte se ha descubierto un epígrafe votivo de un eques de la legio VI, si la lectio es correcta (Jordán Lorenzo, "Precisiones», 268-270). Por otra parte, hay que tener en cuenta que la erección de este monumento funerario no tuvo por qué obligar a L. Sempronius a abandonar su puesto, aunque también pudo disfrutar de un permiso - commeatus - ad hoc (Palao Vicente, "Lejos de casa», 184-190). Otro jinete, C. Valerius Flavinus (CIL, II, 2889), elevó un monumentum para su padre, su madre y su hermano. El epitafio señala que su padre fue veteranus, su hermano miles legionis VII Geminae y él un eques cohortis milliariae. Esta tropa fue probablemente la primera cohorte de la séptima legión (Palao Vicente, Legio VII, 167-168). $77-78$.

22. Saller y Shaw, "Tombstones», 126-127; Meyer, "Explaining the epigraphic habit»,

23. No hemos considerado para este trabajo la inscripción CIL, II, 5238 debido a la incertidumbre que presenta la última línea (Le Roux, L'armée romaine, 226-227). La lectio propuesta por Leite de Vasconcelos ("Aula", 171) y que sigue HEPOL, 22031 (con fotografías del monumento epigráfico) es la siguiente: C(aio) Sulpicio / Pelio Celtif(ilio) / militi co (ho) rtis / Lusitanorum / qui obi(i)t C\{u\}luni/ae ei Cuna f(ecit). La fórmula de la dedicación no es usual en la epigrafía de la región; a lo que hay que sumar la dificultad de interpretación del antropónimo Cuna, no solo por la lectura dudosa de la $u$, sino también debido a que no se aprecian signos formales de separación de letras que aíslen el nombre. 
cuya nomenclatura no se ha conservado (IRPTo, 75) ${ }^{24}$. Tampoco hay indicios de la unidad en la que sirvió, que a todas luces era una auxiliar seguramente enviada fuera de Hispania, puesto que el soldado sería de condición peregrina al igual que su madre debido a la onomástica ${ }^{25}$, a la cronología — segunda mitad del siglo I- y al lugar de hallazgo. Posiblemente estemos ante un cenotafio debido a la ausencia de una dedicatoria que exprese su descanso en la zona, así como otra información relativa a la milicia (unidad, años de servicio). Por otro lado, el monumentum erigido por Albonius Tacillif. es un voto a una divinidad no mencionada (iguerrera?) para que su hijo, Saturninus (CIL, II, 5230) ${ }^{26}$, sirviese bajo buenos auspicios y eludiese la muerte ${ }^{27}$. El cuerpo militar tampoco se menciona en esta inscripción, aunque la onomástica de los dos personajes, de un solo idiónimo, siendo además el antropónimo del padre de naturaleza indígena ${ }^{28}$, les convierte en peregrinos - O ciudadanos latinos si eran miembros del municipio de Collippo en una cronología posterior a la concesión del ius Latii por Vespasiano- ${ }^{29}$, sirviendo el hijo por lo tanto en una unidad auxiliar ${ }^{30}$. Otra relación paternofilial la registramos en una estela de granito desgastada y rota en la parte inferior hallada en Caurium (Coria). En este caso estamos ante un epitafio conjunto en el que aparecen Tongius Virotif., fallecido a los 80 años, y su hijo, Catuenus, un eques peregrino probablemente del ala I Augusta (HEp, 12, 2002, $91)^{31}$, que pereció a los 40 años. Ambos eran oriundos de esta zona ${ }^{32}$. Catuenus aparece identificado como miles eques. El término miles significaría simplemente soldado del ejército romano ${ }^{33}$. Con este vocablo, un peregrino recalca la identidad común a otros soldados, ciudadanos y no ciudadanos, de pertenecer a la comunidad militar, manifestando un esprit de corps común en el mundo castrense. En cuanto a la unidad a la que

24. IRPTo, 75. Ocaña (Toledo): [- - (centuria)]/Caes[i] Celeris/signi<f>(ero) m(ater) Lap/oena Anno(nis filia) / p i i]o filio.

25. Abascal Palazón, Los nombres personales, 396.

26. CIL, II, 5230. S. Sebastião do Freixo (Leiria): Albonius Ta/cilli prof(ilio)/Saturnino / militante/s(olvit) v(otum) l(ibens). El epígrafe está datado en el siglo I o comienzos del II.

27. Le Roux, L'armée romaine, 226.

28. Vallejo Ruiz, Antroponimia indígena, 122-124.

29. Andreu Pintado, "Latinización», 208.

30. Le Roux (L'armée romaine, 226) sugiere una cohorte de lusitanos. Sobre las cohortes reclutadas entre los lusitanos véase Spaul, Cohors², 59-68.

31. HEp, 12, 2002, 91. Coria (Cáceres): Tongius /Viroti an(norum) / LXXX Catue/nus Tongi f(ilius) / miles eques a/lae primae Aug/ustae an(norum) XXXX. González Herrero, "Catuenus", 329-330. El epígrafe se fecha en la primera mitad del siglo I.

32. Vallejo Ruiz, Antroponimia indigena, 266-267 (Catuenus) y 419-420 (Tongius).

33. González Herrero, "Catuenus», 336. 
estaba asignado, los especialistas han propuesto tanto el ala I Singularium civium Romanorum como el ala Augusta. Respecto a la primera unidad militar, pocos académicos consideran plausible una estancia en el solar hispano; por el contrario, el ala Augusta cuenta con más testimonios en la península (CIL, II, 5792; HEp 2, 1990, 656; o incluso la dudosa inscripción $A E, 1997,876$ ), siendo además reconocida su presencia en las provincias hispanas en época julio-claudia ${ }^{34}$. Similar a la lápida funeraria anterior, documentamos el descanso eterno de un padre, Vecius Clutami $f$., y su hijo, Veroblius Veci f., en una inscripción hallada en Lugo. Veroblius fue un soldado de la cohors III Lucensium (CIL, II, 2584) oriundo del noroeste peninsular ${ }^{35}$. Este testimonio, junto con la aparición de una cohors Lucensis en la Notitia Dignitatum ${ }^{36}$, llevaron a algunos especialistas a pensar en esta unidad como parte de la guarnición hispana ${ }^{37}$. No obstante, otros autores plantean dudas acerca de la integración de esta unidad en el dispositivo militar hispano, debido a la diferencia cronológica entre el testimonio epigráfico y la referencia de la Notitia y a la inexistencia de documentación epigráfica en la península ${ }^{38}$.

El parentesco colateral aparece como dedicante en un monumento epigráfico. Una soror, que no mencionó su nombre en la inscripción, conmemoró a su hermano Sempronius Seranus (CIL, II, 2873) ${ }^{39}$, cuyo cargo militar es recogido como miles alae, una forma inusual de indicar su pertenencia a un ala, pero no es un unicum, como tendremos oportunidad de ver en este trabajo. Seranus fue jinete de un ala que desconocemos ${ }^{40}$. El propio Seranus aparece representado en la parte central del monumentum con su panoplia y su caballo. El epígrafe procede de Nova Augusta (Lara de los Infantes), que alcanzó el estatus de municipio en época

34. Palao Vicente, "Las tropas auxiliares», 187-189. Esta unidad abandona la península posiblemente bajo el reinado de Vespasiano, siendo acuartelada en la Tingitana (Spaul, $\mathrm{Ala}^{2}$, 52-53).

35. CIL, II, 2584. Lugo: Vecius Cl/utami f(ilius) Co[- - ]/[- - - - ]/Vero/bli]u/s Veci f(ilius) mil(es) / co(ho)rtis tert/ia(e) Luce(n)s(ium) mil/itavit annis / . - . - - (in latere dextro) MAETARIV ? Este epígrafe se data en el siglo I. Le Roux, L'armée romaine, 336; Meyer, The creation, 128.

36. Not. Dig. Occ., XLII, 29.

37. Roldán Hervás, Hispania, 222-223.

38. Le Roux, L'armée romaine, 150 y 193; Palao Vicente, "Las tropas auxiliares", 177 y 188.

39. CIL, II, 2873. Lara de los Infantes (Burgos): Sempronio/Serano/militi ale / F(- - -) an(norum) $X X /$ soror fra(tri).

40. Gómez-Pantoja («Miles», 284) sugiere la posibilidad de que la unidad sea el ala I Flavia Numidica, con base en África (Spaul, $\left.A l a^{2}, 107-109\right)$. Asimismo, no descarta que sea un cenotafio. 
flavia $^{41}$. En función de la datación de la inscripción estaríamos, quizás, ante ciudadanos latinos provinciales, si realmente eran oriundos de este núcleo urbano ${ }^{42}$.

La esposa tan solo aparece como dedicante en una inscripción. Rustica Galli f. erigió un monumento epigráfico en memoria de Capito Sunnae $f$., decurión de un ala vinculada a la legio X Gemina (CIL, $\mathrm{II}^{2} / 5$, $1136)^{43}$. Ambos individuos eran de condición peregrina a juzgar por su onomástica, por eso consideramos a Capito como soldado auxiliar. En el epígrafe no se menciona la relación existente entre los dos, pero teniendo en cuenta lo comentado anteriormente sobre las motivaciones a la hora de erigir un monumentum sería claramente un nexo conyugal. A pesar de que los soldados del ejército romano tenían prohibido establecer un matrimonio legítimo durante el tiempo que estaban en servicio, este veto no les impidió establecer unos vínculos afectivos con mujeres de su mismo lugar de origen, de la propia comunidad militar o de las proximidades de la zona donde servían ${ }^{44}$. Tanto el miles como la mujer lo consideraban un auténtico matrimonio, ya que en ambos existía el deseo de formar un vínculo conyugal —affectio maritalis - . No hay que olvidar que, aunque las inscripciones no son documentos legales, están reflejando una realidad social. El testimonio epigráfico de Capito, datado en la segunda mitad del siglo I, fue hallado en Urso (Osuna), a priori un lugar extraño para un auxiliar en activo ${ }^{45}$. No obstante, siguiendo la hipótesis de Caballos Rufino, Capito habría fallecido en el año 69, cuando Vitelio envió a la décima legión al sur peninsular, y con ella a las unidades auxiliares que

41. Andreu Pintado, "Latinización», 208.

42. Abásolo Álvarez ("Las estelas», 85) data la inscripción en la primera mitad del siglo II. Por su parte, Curchin («Roman Army Recruitment», 55) ofrece un marco cronológico más amplio, siglos I o II.

43. CIL, II $2 / 5,1136$. Osuna (Sevilla): Capito Sunnae f(ilius) / decurio equit(um) / alae geminae leg(ionis) X/Rustica Galli f(ilia).

44. Greene, "Conubium", 137-138. Tradicionalmente se ha aceptado por la mayor parte de los especialistas el fin de la prohibición que tenían los soldados romanos para contraer matrimonio en virtud de los privilegios otorgados por el emperador Septimio Severo (Phang, The marriage, passim). En contra de esta hipótesis vid. Speidel, «Les femmes», 208. Recientemente, Mongelli «Il matrimonio», 179-180. Sobre este debate historiográfico véase López Casado, Idem in me, 25, n. 17.

45. Dado el lugar de hallazgo de la inscripción podría pensarse que Capito era un veterano asentado en Urso, siendo un incola de la colonia casado con una indígena romanizada. Sin embargo, le consideramos activo porque si fuera veterano, en función de la datación del epígrafe, debería mostrar una onomástica trinominal, haciendo gala del derecho de ciudadanía, un distintivo de excelencia social más en una época temprana. El emperador Claudio concedió, ya de manera regular, la ciudadanía romana y el ius connubii a los auxiliares licenciados. 
tenía adscritas, para hacer frente a Lucceius Albinus, procurador de las Mauritanias y partidario de Otón ${ }^{46}$.

Al margen de lo anterior, podemos incluir también en los grupos de parentesco la conmemoración colectiva de una comunidad suprafamiliar a uno de sus miembros, el jinete Aemilius Balaesus (HEp, 7, 1997, 1173) ${ }^{47}$. Este soldado era signifer del ala Sabiniana, una unidad identificada con el ala I Pannoniorum Sabiniana, acuartelada en Britannia a partir de época de Adriano ${ }^{48}$. No se descarta una posible estancia de esta unidad en el solar hispano antes de su partida a Britannia debido a la diferencia cronológica entre esta inscripción — datada a finales del siglo I- y los primeros vestigios de la presencia del ala en la isla - reinado de Adriano- ${ }^{49}$. Aemilius Balaesus falleció estando en servicio y fue conmemorado por su cognatio - grupo humano unido por lazos de parentesco- de donde era natural. Roma respetó esta forma de estructura social indígena pues no suponía ningún peligro para su dominación política ${ }^{50}$. En función de la onomástica, el signifer debió de disfrutar de un estatuto jurídico privilegiado, siendo ciudadano romano - heredado del padre- o, cuando menos, latino.

Fuera de los núcleos familiares documentamos principalmente la dedicación por parte del compañero de armas, que además es nombrado heredero. Estas relaciones se constatan en tres inscripciones. El origen foráneo de estos soldados favorecía este tipo de conmemoración. Iulius Longinus Doles Biticentif., eques del ala Tauriana, fue conmemorado por sus herederos Sulpicius Susulla y por Fuscus Bithus tras su muerte a los 40 años (CIL, II, 2984) $)^{51}$. Doles era de la tribu tracia de los Bessos y fue reclutado a los 18 años. Sus dedicantes también eran tracios, tal vez de la misma tribu, puesto que así lo indican sus cognomina ${ }^{52}$, y seguramente

46. Caballos Rufino, El nuevo bronce de Osuna, 428. Asimismo, plantea la posibilidad de que la unidad de Capito fuera el ala II Gallorum Sebosiana, puesto que formaba parte de los auxilia de la legio X Gemina.

47. HEp, 7, 1997, 1173. Aldeia Nova (Miranda do Douro, Bragança): Aemilio Bal/aeso sigini/fero (sic) alae Sa/binianiae cogn/atio de(dicavit) gen(tili) s(uo). González Rodríguez y Ramírez Sánchez («Unidades organizativas», 254, n. 2) reconstruyen la última línea con el nombre de la cognatio: Decen[icorum/orum].

48. Spaul, Ala $^{2}, 189-190$.

49. Palao Vicente, «Las tropas auxiliares», 179.

50. Royo Martínez, "Onomástica», 387.

51. CIL, II, 2984. Calahorra (La Rioja): Iulius Lon/ginus Doles / Biticenti f(ilius) Bes/ sus eques alae / Tau (rianae) tor(quatae) vic(tricis) c(ivium) R(omanorum) / an(norum) XL aer(um) XXII h(ic) s(itus) e(st). / Sulpicius Susulla / et Fuscus Bitius / h(eredes) ex t(estamento) $f($ aciendum) c(uraverunt). El monumentum está datado en época flavia.

52. Dana, Onomasticon, 54 (Bithus) y 341 (Susulla). 
eran commilitones del difunto. Tanto Doles como Susulla eran ciudadanos romanos. El primero probablemente heredó la ciudadanía de su padre, mientras que el segundo pudo recibirla del emperador Galba, quizás en el momento de licenciarse ${ }^{53}$. En cuanto al tercer individuo, la lectura aportada por el CIL y seguida por la mayor parte de los investigadores es Fuscus Bitius, entendido bien como una inversión onomástica, o bien como doble cognomina. En el primer caso nos encontramos con una nomenclatura compatible con un estatuto jurídico privilegiado. En este sentido, el soldado pudo haber accedido a la ciudadanía en virtud de la concesión del título civium Romanorum al ala tras ayudar a sofocar la revuelta bátava $^{54}$, aunque resultaría ciertamente significativo que no optase por el gentilicio Flavius, dado que fue Vespasiano el que otorgó este privilegio al ala. Sin embargo, creemos más acertada la lectura de Bithus en vez de Bitius, realizada por Dana ${ }^{55}$. Este doble idiónimo encajaría mejor con su procedencia tracia y una condición peregrina, debiendo ser su reclutamiento posterior a la concesión de la ciudadanía romana a la unidad ${ }^{56}$. El ala Tauriana debió de estar estacionada en las cercanías de Calagurris (Calahorra) ${ }^{57}$. Otro eques conmemorado por su commanipularis fue Domitius [---] (ERPLe, 152) ${ }^{58}$. Este jinete militó en el ala II Flavia Hispanorum civium Romanorum ${ }^{59}$. Murió a los 37 años, habiendo servido 17,

53. San Vicente González de Aspuru, "Galba», 96-98. Según este autor Sulpicius Susulla se asentaría en los aledaños del campamento de su antigua unidad.

54. Holder, Studies in the Auxilia, 36. Los especialistas consideran que el título civium Romanorum, otorgado como recompensa por una acción heroica a las unidades auxiliares, se comenzó a conceder en época flavia (Kraft, Zur Rekrutierung, 150-151; Haynes, Blood of the Provinces, 63). No obstante, algunos académicos sostienen que este privilegio ya se otorgaba en época pre-flavia (Maxfield, The military decorations, 232).

55. Dana, "L'impact», 54; Dana, Onomasticon, 54.

56. Los soldados romanos podían instituir como herederos en su testamento a peregrinos y latinos junianos (Gayo, Inst., 2, 110). No conocemos con certeza cuándo se implantó esta medida. Algunos autores piensan que puede atribuirse a Trajano (Campbell, "The marriage", 158).

57. Christol y Le Roux, "L'aile Tauriana», 21. Es difícil establecer una fecha de entrada del ala Tauriana en Hispania en época julio-claudia. En el 69 está acantonada en Lyon, participando posteriormente en la guerra contra Civilis para después regresar a la península hasta su partida a Mauretania Tingitana antes del año 88 (Holder, Studies in the Auxilia, 36; San Vicente González de Aspuru, «Galba», 99-103).

58. ERPLe, 152. Astorga (León): [--- Do]mitio / [---]o eq(uiti) alae / II Fllavi]ae $H$ (ispanorum) c(ivium) R(omanorum)/domo Tabala/ca an(norum) XXXVII aer(orum) / XVII C(aius) Corne/lius Serenus / eq(ues) alae eiusd(em) / municipi heres / exs voluntate / f(aciendum) c(uravit).

59. Esta unidad fue asignada a la legio VII Gemina. Estuvo acuartelada en Petavonium (Rosinos de Vidriales, Zamora) de forma permanente desde finales del siglo I hasta, al menos, mediados del siglo III, a tenor de las fuentes epigráficas. La Notitia Dignitatum 
por lo que su reclutamiento se produjo a los 20 años. Su hermano de armas y compatriota, C. Cornelius Serenus, fue quien se encargó de erigir el monumentum. Ambos eran naturales de Tabalaca, una ciudad desconocida, situada probablemente en el norte de África ${ }^{60}$. El epígrafe, datado a caballo entre la primera y la segunda centuria, fue hallado en la capital del conventus de los astures, donde los equites podrían estar sirviendo en el officium de algún cargo político o en una determinada misión ${ }^{61}$. Finalmente, Iulius Capito falleció a los 33 años en la zona noroeste peninsular (ERPLe, 181) ${ }^{62}$. Allí su compañero y heredero, Laelius Decuminus, honró su memoria. La unidad en la que servían pudo ser la cohors I Celtiberorum o la cohors I Gallica, sin poder precisar cuál de las dos, ya que la inscripción presenta una fractura en la parte superior derecha, rompiendo justamente el trazado de la $\mathrm{C}$ o de la $\mathrm{G}^{63}$. Además, ambas cohortes colaboraron en la explotación del oro en esta región ${ }^{64}$. Los soldados pudieron haber sido hispanos.

documenta una cohors II Flavia Pacatiana, que pudo ser su sucesora. (Jiménez de Furundarena, "Historia y prosopografía del Ala II Flavia», 203-211).

60. Roldán Hervás, Hispania, 213; Le Roux, L'armée romaine, 217. Por el contrario, otros autores piensan que podían ser oriundos del noroeste peninsular (Santos Yanguas, El ejército, 238; Santos Yanguas, "Soldados astures», 28-31; Pitillas Salañer, "La figura", 153).

61. Jiménez de Furundarena («Historia y prosopografía del Ala II Flavia», 225) propone el officium del Legatus Iuridicus o del Procurator Metallorum.

62. ERPLe, 181. Luyego de Somoza (León): D(is) M(anibus)/Iul(io) Capito[ni]/mil(iti) coh(ortis) I C[elt(iberorum)] o G[al(licae)]/an(norum) XXXIII sti/p(endiorum) ---]/(centuria) Val(erii) Caelian[i]/ h(ic) s(itus) est s(it) t(ibi) t(erra) l(evis) La[e]/[li]us Decuminu[s] / commanipu[l(aris)] / h(eres) f(aciendum) [c(uravit)]. El epígrafe se fecha en la primera mitad del siglo II (en el segundo tercio según Jiménez de Furundarena, «Historia y prosopografía de la cohors I Celtiberorum»,117).

63. Jiménez de Furundarena ("Historia y prosopografía de la cohors I Celtiberorum», 117) incluye a los soldados en la cohors I Celtiberorum; por el contrario, Santos Yanguas ("Oficiales astures», 126) aboga por la cohors I Gallica. También Spaul (Cohors², 153) se decanta por esta última unidad. Ambas cohortes formaron parte del exercitus hispanicus hasta el Bajo Imperio, si bien la cohorte Gallica llegó en época julio-claudia (Jiménez de Furundarena, "Historia y prosopografía de la cohors I Gallica», 78-81), la Celtiberorum lo hizo durante el reinado de Adriano (Jiménez de Furundarena, «Historia y prosopografía de la cohors I Celtiberorum", 101-105). Cidadela, en A Coruña, fue el lugar de acantonamiento de la cohors I Celtiberorum, mientras que para la cohors I Gallica se han propuesto como lugares de acuartelamiento Aquae Querquennae (Baños de Bande, Ourense) y Pisoraca (Herrera de Pisuerga, Palencia) (Jiménez de Furundarena, «Historia y prosopografía de la cohors I Gallica", 80). Sobre los problemas de identificación de una o varias cohortes I Celtiberorum véase Costa García, «Tras los pasos».

64. Jiménez de Furundarena, "Historia y prosopografía de la cohors I Celtiberorum», 104; Jiménez de Furundarena, "Historia y prosopografía de la cohors I Gallica», 81. 
También constatamos en este estudio el vínculo de la amistad. Elanus se encargó de conmemorar a su amigo Pentovius Elaesus $(A E, 1982,580)^{65}$. Este aparece como miles ala, fórmula recogida en el monumento epigráfico de Sempronius Seranus (CIL, II, $2873)^{66}$. La unidad a la que estaba asignado el militar no se ha conservado. Jiménez de Furundarena le incluye, aunque sin total certeza, en el ala II Flavia ${ }^{67}$, algo plausible a tenor de la cronología del epígrafe — siglo II- ${ }^{68}$, puesto que para esa época las bajas producidas en este destacamento se completarían con reclutas locales ${ }^{69}$. Tanto el militar como su amigo eran peregrini vadinienses ${ }^{70}$.

Un monumento epigráfico registra una relación de dependencia. L. Campilius Paternus, asignado al ala II Flavia (ERPLe, 136) ${ }^{71}$, fue conmemorado, quizá por un familiar, a través de su liberto Flavius Campilius Nofirus. La inscripción está fragmentada en dos partes, lo que impide la reconstrucción de las líneas cuatro y cinco. Hübner reconstruyó tribuni militum de la legio VII Gemina, algo inverosímil en la carrera militar de un auxiliar. Por su parte, Le Roux propuso opt(io) [equitum / leg(ionis) VII G(eminae) F(elicis)] $]^{72}$, ascendiendo Paternus a la caballería legionaria con

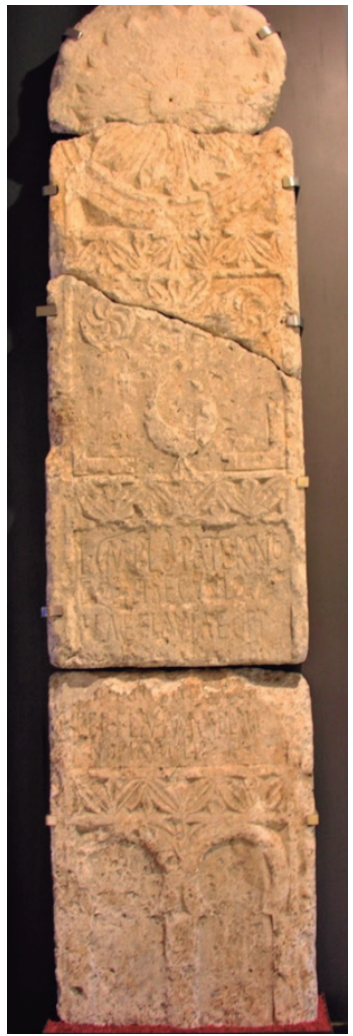

Estela funeraria de L. Campilius Paternus. Fotografía del autor. Museo de León.

65. $A E, 1982$, 580. Santa Olaja de la Varga (León): M(onumentum) / [Pe]ntovio Ela/ [es]o militi a(lae?) / [---] Vad(iniensi) an(norum) XXV / [Ela]nus(?) Arga / [am]ico p(osuit) h(ic) s(itus) e(st).

66. Otros ejemplos: $A E, 1940,5 ; A E, 1976,746$.

67. Jiménez de Furundarena, "Historia y prosopografía del Ala II Flavia», 226.

68. Martino García, "Acerca de la cronología», 317.

69. Cheesman, The Auxilia, 79; Holder, Studies in the Auxilia, 124.

70. Elanus aparece acompañado de otro nombre que ha sido interpretado como un segundo idiónimo - Arga(elus) según ERPLe, 388- o como la gentilidad a la que pertenecía, Argaum (González Rodríguez, Las unidades organizativas, 150, n. ${ }^{\circ} 36$ ).

71. ERPLe, 136. León: L(ucio) Campilio Paterno / equiti secundae / alae Flaviae opt(io) / [- - -]/[- - -]/per Flavium Campilium / Nofirum lib(ertum) f(aciendum) c(uravit). El epígrafe se data a principios del siglo II.

72. Le Roux, L'armée romaine, 217. 
el rango de optio, siendo el segundo al mando de los jinetes legionarios. Por el contrario, Pavkovič piensa en un traslado a la inversa, de los equites legionis a los auxilia con un cargo $^{73}$. La onomástica nos hace pensar en un ciudadano romano, quizá con ascendencia italiana — tal vez hijo de un soldado veterano, probablemente un antiguo legionario asentado en el núcleo civil existente junto al campamento- ${ }^{74}$. El hallazgo de la inscripción en León (extraída de la muralla) no es algo concluyente a favor de una u otra idea, pues si bien favorecería, a priori, la idea del ascenso a la caballería legionaria; si hubiera militado anteriormente en la legión, como piensa Pavkovič, o desciende de un veterano legionario, sería en Legio donde estarían sus primeros camaradas y/o su familia.

Los milites auxiliares también se encargaron de recordar la memoria de sus seres queridos, cumpliendo así con la piedad filial ${ }^{75}$. El centurión Reburrus Taporif. conmemoró a su madre, Bolosea Brevi f., que murió a los 70 años $(E R P S a, 107)^{76}$. La onomástica de este grupo familiar nos remite a un ambiente lusitano ${ }^{77}$. Desconocemos la unidad donde militó este centurión peregrino, aunque probablemente dicho destacamento auxiliar no se encontraba acuartelado en Hispania ${ }^{78}$. Pese a que Reburrus estaría lejos de su patria se encargó de costear un monumentum para su difunta madre. Asimismo, el jinete Flavos conmemoró a ambos progenitores (HEp, 5, 1995, $207)^{79}$. El nombre del padre no se ha conservado, tan solo sabemos su

73. Pavkovič, The legionary horsemen, $72-76$ y 135-136. Cf. Holder, Studies in the Auxilia, 140. El optio era el segundo al mando en una centuria. Asimismo, sería el segundo al mando en una turma. No obstante, en este caso, y apoyándonos en las fuentes epigráficas, documentamos mayormente el título de duplicarius, el cual sería probablemente usado como alternativa a optio (Breeze, "Pay Grades", 133. AE, 1899, 27; CIL, III, 5924; RIB, I, 405). Le Roux, "Duplicarius», 527-528.

74. Según el opel, II, 29 el nomen Campilius se ha constatado fundamentalmente en Italia, donde se registran diez de las doce inscripciones que atestiguan este gentilicio.

75. En este grupo se podría incluir la inscripción, hoy perdida, de CIL, II, 5963. Es un epitafio de una niña erigido por sus progenitores. Una nueva interpretación del texto ha asignado al padre el grado de sesquiplicarius (HEp, 9, 1999, 23). Epigráficamente, este término está relacionado con un rango militar de la caballería romana más que con una referencia al stipendium. Sobre el mismo vid. Le Roux, "Duplicarius", 523-532.

76. ERPSa, 107. San Martín del Castañar (Salamanca): Bolosea / Brevi f(ilia) vixit / an(nos) LXX b(ic) s(ita) e(st) / s(it) t(ibi) t(erra) l(evis) / Reburrus / Taporif(ilius) ce/nturio / matri. La cronología de este epígrafe no es la que indica el corpus ERPSa, segunda mitad del siglo II-inicios del siglo III, sino que sería del siglo I, entre el segundo y el tercer tercio de esa centuria según Palao Vicente, "Reburus Taporif.», 72.

77. Vallejo Ruiz, Antroponimia indigena, 213-214 (Bolosea) y 384-387 (Reburrus).

78. Palao Vicente, «Reburus Tapori f.", 172-173.

79. HEp, 5, 1995, 207. Granadilla (Cáceres): - - - - / Cilisi f(ilius) / an(norum) LX/ Boetela / Cili f(ilia) [an(norum)] LI / b(ic) s(iti) s(unt) s(it) [v(obis) t(erra)] l(evis) / Flavos / eq(ues) patri / et m(atri)f(aciendum) c(uravit). 
filiación y la edad de su muerte —60 años-; por otra parte, su madre, Boetela Cili f., murió más joven — 51 años-. En función de la onomástica el grupo familiar tendría una condición peregrina y sería natural de la zona $^{80}$. El eques comenzaría la carrera en época flavia, aunque en la inscripción omitió su unidad. Esta pudo haber sido unas de las acuarteladas en Hispania, puesto que bajo los flavios se implementó el reclutamiento provincial al mismo tiempo que decayó el número de reclutas enrolados en unidades salidas de sus zonas de origen ${ }^{81}$. En este caso contamos con la cohors I Gallica equitata civium Romanorum, el ala II Flavia, la cohors I Celtiberorum equitata civium Romanorum —-si bien más tardía cronológicamente-, el ala Tauriana —aunque abandona la península en época de Domiciano - y el ala Sabiniana, si se acepta la posibilidad de una estancia en la península entre finales del siglo I y el reinado de Adriano. Por otro lado, recientemente, una nueva lectura de un epígrafe abulense $(C I L, \text { II, 5866 })^{82}$ ha aportado un posible jinete del ala Hispanorum Vettonum civium Romanorum ${ }^{83}$. Además, según esta lectura era sesquiplicarius, es decir, el tercero al mando de la unidad ${ }^{84}$. El eques en cuestión portaba un solo idiónimo, aunque romanizado — Longinus - , dada su condición de peregrino, y erigió el monumento epigráfico en memoria de Matugenus Cadani f., de los Turaedos. Tanto Longinus como Matugenus serían naturales de estas tierras, aunque no sabemos el vínculo que les unía y que llevó al militar a erigir el epitafio (¿commilitones?) ${ }^{85}$. En cuanto a la unidad en la que militaba Longinus, el ala Hispanorum Vettonum civium Romanorum, fue reclutada en época julio-claudia ${ }^{86}$; tras-

80. Boetela parece ser es un hápax en la epigrafía hispana. No obstante, tal vez pueda estar relacionado con otros nombres lusitanos como Boutius, Boutia, etc. (Salas Martín y González Cordero, «Nuevas aportaciones», 188; Vallejo Ruiz, Antroponimia indígena, 278281). Por otra parte, dado que el epígrafe se data a finales del siglo I o comienzos del II y que se encontró reutilizado como jamba en la puerta de la Villa no sabemos con certeza la procedencia exacta de esta familia. La onomástica de nombre único les incluye en la condición de peregrini. Sin embargo, cerca del lugar de hallazgo de la pieza encontramos municipia de promoción flavia como Capera o Caurium (Andreu Pintado, "Latinización", 208), por lo que, si fueran oriundos de estos núcleos, estaríamos ante ciudadanos latinos.

81. Holder, Studies in the Auxilia, 118-124.

82. CIL, II, 5866. Ávila: Matugeno / Turaedoqu(m) / Cadani f(ilio) / Longinus / Sesquenium / S[- - - - - -]IE Sala/[- - - ionum / [- -] d(e) s(uo) p(osuerunt). HEp, 18, 2009, 23: Matugeno / Turaedoqu(m) / Cadani f(ilio) / Longinus / sesqu(i)plicar/i(u)s [- - -] / [eq] ues ala(e) / [Vet]tonum / d(e)s(uo) p(osuit) o Matugeno / Turaedoqu(m) / Cadani f(ilio) / Longinus / sesqu(i)plicar/i(us) S[- - -]/[eq]ues ala(e) / [Vet]tonum / d(e) s(uo) p(osuit).

83. Hernando Sobrino, "A propósito", 273-286.

84. Holder, Studies in the Auxilia, 95 y 153

85. Hernando Sobrino, "A propósito», 284.

86. Alföldy («Neue und revidierte», 519) señala que posiblemente fuese formada bajo Augusto. 
ladada posteriormente a Britannia, pudo formar parte de la expedición para la conquista de la isla proyectada por Claudio ${ }^{87}$. De ser correcta esta lectio estaríamos ante el segundo jinete del ala de los vetones hallado en Hispania $^{88}$. Ambos epígrafes se fechan en la primera mitad del siglo I, como muy tarde en época de Claudio ${ }^{89}$. Este hecho ha llevado a plantear a algunos especialistas una posible estancia de esta unidad en la península antes de su partida a Britannia $^{90}$.

Los soldados auxiliares no solo van a erigir monumentos epigráficos de tipología funeraria para sus seres queridos, sino que también hallamos testimonios de tipología honorífica erigidos a sus oficiales superiores. Estas inscripciones no evidencian relaciones sociales de facto, sino más bien relaciones de jerarquía o de poder. En este sentido, la epigrafía, en la cual tanto los dedicantes como los dedicados son militares, refleja una conciencia o sentido de pertenencia a un grupo concreto de la sociedad romana, en este caso el ejército, una institución jerarquizada, con una ideología y unas normas exclusivas. Los soldados desarrollaron un sentimiento de identidad común, de pertenencia a una comunidad humana en la que convivían, compartiendo los placeres de la vida y las desgracias de la guerra. Esa autoafirmación identitaria de los milites, que buscaban distinguirse de la sociedad civil, se hace patente también con una vestimenta exclusiva (caligae, balteus — cinturón militar-, sagum) que exhibían con orgullo y de la que despojarlos suponía una humillación. Al soldado se le reconocía por su vestimenta y sus modales, tal y como expresó Apuleyo. En definitiva, estos monumenta manifiestan un esprit de corps iniciado en el momento de pronunciar el sacramentum militiae; un sacramento que les impedía abandonar la línea salvo, entre otras cuestiones, para salvar a un compatriota. En este sentido, el eques [L.] Marcius Maternus honró a L. Marcius Avitus, praefectus alae I Singularium civium Romanorum $(A E, 1961,358)^{91}$. En la inscripción que hemos señalado, Marcio Materno nos aparece como jinete, pero llegó a ser promocionado a decurión ${ }^{92}$ y alcanzó la honesta missio $0^{93}$. Tras la licencia se retiró en su lugar de origen,

87. Holder, The Roman Army, 110.

88. $A E, 1986,426$.

89. Hernando Sobrino, "A propósito", 284.

90. Roxan (The auxilia , 491) apunta una estancia en el solar hispano hasta bien entrada la época tiberiana. Alföldy, «Neue und revidierte», 517-519.

91. AE, 1961, 358. Idanha-a-Velha (Castelo Branco): L(ucio) Marci[o] / Fusci f(ilio) Quir(ina) Avit[o] / praef(ecto) fabr(um) / praef(ecto) coh(ortis) I S[u]/ror(um) sagitta[r(iorum)] / trib(uno) mil(itum) leg(ionis) X Freten[sis] / praef(ecto) eq(uitum) alae I Sing[u]/lar(ium) c(ivium) R(omanorum) donis dona[to] / Marcius Maternus e[qu]/es alae eiusdem praefe[cto] / optumo ob merito.

92. $A E, 1961,359$.

93. Materiaes, n. ${ }^{\circ}$ 4, 2019: 100-102. 
la civitas Igaeditanorum. Entre ambos quizá existió una relación clientelar, apoyada en una misma procedencia lusitana, que favoreció que el prefecto enrolara a su compatriota en su unidad ${ }^{94}$; otra opción, fijándonos en la onomástica, sería la obtención de ciudadanía del soldado cuando el prefecto comandaba el ala $^{95}$. La mayor parte de los especialistas no consideran a esta unidad como parte del exercitus hispanicus ${ }^{9}$. El otro monumento epigráfico de tipología honorífica también fue erigido por un eques, P. Perellius Maximus, decurión del ala II Thracum (AE, 2008, 666) ${ }^{97}$. El nombre del oficial no se conserva, así como tampoco sus milicias ecuestres - tan solo el tribunado militar-. Este personaje del orden ecuestre, natural de Carteia, debió de cumplir con las tres militiae, ocupando la prefectura del ala II Thracum antes de ser nombrado procurador ${ }^{98}$. El decurión, cuya onomástica nos remite a un origen africano, honraría a su antiguo comandante erigiéndole un monumentum en su ciudad natal. En este caso no tenemos la certeza de cuáles serían los vínculos entre ambos, más allá de la jerarquía militar.

\section{LAS RELACIONES SOCIALES DE LOS AUXILIARES VETERANOS ${ }^{99}$}

Los monumentos epigráficos que constatan relaciones sociales de los auxiliares veteranos son solamente tres. Un veterano lusitano regresó a su

94. Le Roux, L'armée romaine, 225.

95. Roldán Hervás, Hispania, 224-225.

96. Palao Vicente, "Las tropas auxiliares", 188.

97. AE, 2008, 666. San Roque (Cádiz): - - - - - / Claudiae P[iae Fidelis]/proc(uratori) Aug(usti) r[ation(is)] / Putiolanae ab ann[ona] / P(ublius) Perellius Maxi[mus] / dec(urio) alae [II] / Thracum /d(ono) [d(edit)]. La inscripción se fecha en el siglo II, en época de Adriano o de Antonino Pío.

98. Alföldy, «Ein Prokurator», 168.

99. En el caso de los veteranos, destacamos varios testimonios epigráficos que no presentan el cuerpo donde sirvieron y que han sido adscritos a unidades auxiliares, sin que exista una total certeza, por lo que no han sido incluidos en el estudio. El caso más notorio es el de L. Visellius Niger (CIRPBu, 555). Para algunos especialistas, la ausencia de mención de la unidad se explicaría quizá por el servicio en unidades auxiliares de corta existencia (Perea Yébenes, "Notas", 203). Sin embargo, la omisión de la unidad militar no se vincula automáticamente a los auxilia, ya que, aunque es una fórmula inusual, encontramos testimonios de otros veteranos cuyos epígrafes no indican la unidad, pero que por el lugar de hallazgo y la cronología podemos afirmar que sirvieron en una legión ( $A E$, 1911, 91; CIL, III, 3669; CIL, III, 14417; CIL, VIII, 3011; RIB, 358; RIB, 517; RIB, 526). Encontramos paralelos también entre los jinetes legionarios $(R I B, 522)$. Otros autores prefieren incluir a L. Vissellius Niger en una legión de las que estaban acuarteladas en Hispania — la IIII, la VI o la X- (Abásolo Álvarez, «Sobre algunas escuelas», 203). De la misma manera, el revisor de $A E, 2010,676$, consideró, reconociendo que sin total certeza, la posibilidad de que M. Iulius Maternus pudiera ser un veterano auxiliar debido a la ausencia de unidad en el monumento epigráfico. 
lugar de origen tras luchar en la cohors II Lusitanorum (EE, VIII, 14) ${ }^{100}$. Toncius Toncetami f., natural de la civitas Igaeditanorum, erigió un altar a la diosa Victoria. A pesar de ser veterano conservó una nomenclatura indígena debido a la datación temprana del epígrafe (primera mitad del siglo I, anterior a los privilegios concedidos por Claudio a los veteranos auxiliares). En la base del monumentum se puede leer: Ardunnus Comini f. $f e$ (cit). La relación entre ambos no se constata en la pieza. Quizá fue un amigo en el que delegó el veterano para cumplir su voto por diversas circunstancias ${ }^{101}$.

Aemilius Flavus (ILCAM, 90) ${ }^{102}$, un veterano (missicius) de un cuerpo militar desconocido, falleció a los 55 años, siendo recordada su memoria por su hijo Saturninus. Las razones que hacen factible una posible adscripción a una unidad auxiliar son fundamentalmente dos. Por una parte, Aemilius Flavus, miembro de la gentilidad de los Eturicos ${ }^{103}$, constatada en territorio carpetano, carecería de la ciudadanía romana. Por lo tanto, su reclutamiento debió de realizarse en una unidad auxiliar, recibiendo tras la honesta missio la preciada civitas Romana. Por otro lado, la onomástica de su hijo, de un único idiónimo, indicaría una ausencia de un estatuto jurídico privilegiado. Esto podría estar relacionado con la reforma que Antonino Pío llevó a cabo en los auxilia en el 140 y que se refleja en los diplomas militares. El emperador redujo los privilegios de los veteranos auxiliares al suprimir la cláusula que otorgaba la ciudadanía romana a los hijos nacidos durante el servicio militar de sus padres ${ }^{104}$. De esta manera, Saturninus sería concebido mientras Aemilius Flavus estaba en activo y el licenciamiento de este se produciría en un momento posterior al año 140. Otra variable es que fuera engendrado en un momento anterior al alistamiento del padre.

Finalmente, un veterano auxiliar y su esposa se establecieron en Mérida hasta el final de sus días (HEp, 18, 2009, 32) ${ }^{105}$. La inscripción no

100. EE, VIII, 14. Fundão (Castelo Branco): [T]oncius/ [T]oncetami / f(ilius) v(eteranus) miles / signifer / coh(ortis) II Lus(itanorum) Viqtoriae (sic) / v(otum) s(olvit) l(ibens) m(erito) / Ardunnus / Comini f(ilius) fe(cit).

101. Atendiendo al verbo fecit, tal vez se entienda en sentido literal y Ardunnus fuera el artesano que elaboró el monumento epigráfico (Cebrián Fernández, Titvlvm fecit, 24; Abascal Palazón, "Oficinas", 163-164).

102. ILCAM, 90. Perales de Milla (Madrid): D(is) M(anibus) / Aem(ilio) Flavo / Eturico(n?) mis/sicio an(norum) LV/Saturninu/s filius po/suit s(it) t(ibi) t(erra) l(evis). El epígrafe está datado en el siglo II.

103. Royo Martínez, "Onomástica», 388.

104. Waebens, «Imperial policy», 5.

105. HEp, 18, 2009, 32. Mérida: [D(is)] M(anibus) s(acrum) / [- - -JILIS vet(eranus) al(a)e (Miliariae) orig(ine) / [Numidic(us) ? castel]lo Bagai(ensi) an(norum) LXI / [h(ic) 
se ha conservado de forma íntegra, por lo que la onomástica del veterano se desconoce y de la de la mujer no se tiene una total certeza. La cuestión que nos atañe militarmente es ¿qué hace en Emerita un auxiliar de un ala miliaria oriundo de Numidia a finales del siglo II-inicios del III? En Hispania no hubo acuartelada ningún ala miliaria, unidades creadas a partir de los flavios ${ }^{106}$. Este veterano debió de militar en una unidad semejante acantonada en Mauretania Caesarensis ${ }^{107}$. Ignoramos los motivos de su presencia en Mérida, pues los veteranos solían retirarse en las cercanías de los lugares donde habían servido ${ }^{108}$. No obstante, hay que tener en cuenta que, en Hispania, los veteranos prefirieron asentarse mayoritariamente en núcleos urbanos que disfrutaban de estatutos jurídicos privilegiados. Estos núcleos contaban con mayores posibilidades económicas y sociales que facilitaban la inserción del antiguo soldado en la sociedad civil. Además, Augusta Emerita era una ciudad donde el elemento militar estaba presente, no solo por su fundación con veteranos - lejana en el tiempo en época de este antiguo soldado númida-, sino también, y fundamentalmente, porque como capital provincial contaba con efectivos al mando del gobernador provincial. Desconocemos los motivos que llevaron a este veterano a elegir, de forma premeditada, pues murió a los 61 años, la capital lusitana como lugar de retiro ${ }^{109}$.

Al margen de las categorías de análisis, documentamos dos inscripciones que podemos catalogar como incerti, pues no tenemos la total certeza de que los militares que aparecen en ellas fueran veteranos o siguieran en activo. En la provincia de Zamora hallamos el epígrafe funerario que Arro dedicó a su hermano, un eques del ala II de los tracios (CIRPZa, 240) ${ }^{110}$. Lamentablemente, las primeras líneas, donde vendría la onomástica del militar y su rango, no se han conservado. Arro es un antropónimo que

s(itus) e(st) s(it) t(ibi) t(erra) l(evis) baec] dom(us) aeterna / [mibi erit et ux]ori meae Alli/[ae ? - - -] item [v(ixit)] a (nnis) LV/[emi locum ? memo]riae et pon/[i iussi Emer(itae) ?] titulum feci /ut genus innotu[m sic i]nnotescere / possit nam tu qui le/gis - - ]s (e)st in eo / [c]um tibi datum [- - velnies.

106. Holder, Studies in the Auxilia, 5-6.

107. Le Roux y Ramírez Sádaba, "Un nuevo testimonio», 300. Sobre las alae de esta provincia vid. Benseddik, Les troupes auxiliaires, 23 y ss.

108. Mann, Legionary Recruitment, 62.

109. Le Roux y Ramírez Sádaba ("Un nuevo testimonio", 302) abogan por una posible estancia del veterano en Mérida realizando alguna misión administrativa, más que por una acción bélica de su unidad en la Lusitania. También sugieren la idea de una unión conyugal con una mujer de la provincia, lo que haría que el veterano se asentase en la capital. fratri.

110. CIRPZa, 240. Villalcampo (Zamora): -----/alae sec(undae) T(h)r/acum Arro / 
está bien atestiguado en Hispania ${ }^{111}$, particularmente en el norte peninsular, siendo ambos probablemente de origen astur ${ }^{112}$. El ala II Thracum estaba acantonada en la Mauretania Caesarensis, si bien, pudo formar parte del exercitus hispanicus en época julio-claudia hasta mediados de la primera centuria ${ }^{113}$. No obstante, a pesar de su estacionamiento en África, reclutas hispanos siguieron nutriendo sus filas ${ }^{114}$. No sabemos con certeza si este jinete alcanzó el rango de veterano, regresando a su tierra natal ${ }^{115}$, o, por el contrario, murió en activo en África y su hermano le erigió un cenotafio $^{116}$. El otro soldado considerado aquí es Q. Caecilius Varica ( $A E$, $1993,915)^{117}$. Varica formó parte de la cohorte Antistiana praetoria, una unidad auxiliar ${ }^{118}$, probablemente vinculada con el legado de Augusto contra los astures, C. Antistius Vetus. El empleo del nombre del general en jefe o del comandante del destacamento para referirse a la unidad siguió siendo una práctica habitual hasta la época tiberiana al menos ${ }^{119}$. Por otro lado, el calificativo praetoriae de la cohorte, empleado desde época republicana, confiere una consideración específica a la unidad como guardia personal de un alto mando militar ${ }^{120}$. Una de las incertidumbres que se presentan es el rango del militar, si falleció tras la licencia o en activo ${ }^{121}$. Otra es la ubicación de la propia unidad, pues no sabemos dónde estaría sirviendo cuando se incorporó Varica ${ }^{122}$. Tampoco sabemos con certeza el parentesco que guarda con T. Caecilius Calventius, pudiendo ser su hermano o su hijo ${ }^{123}$. Ambos están inscritos en la tribu Papiria, lo que

111. Abascal Palazón, Los nombres personales, 286-287.

112. Le Roux, L'armée romaine, 227.

113. Roldán Hervás, Hispania, 216; Benseddik, "Les troupes auxiliaires», 44; Spaul, Ala $^{2}, 231-233$.

114. Le Roux, L'armée romaine, 87.

115. Palao Vicente, «Presencia militar», 50.

116. Le Roux, L'armée romaine, 227.

117. AE, 1993, 915. Mérida: Q(uintus) Caecilius Q(uinti) f(ilius) Pap(iria) / Varica / cohortis Antistianae / praetoriae / T(itus) Caecilius Q(uinti) f(ilius) Pap(iria) Calventius / Caecilia T(iti) l(iberta) Urbana h(ic) s(iti) s(unt).

118. Le Roux y Ramírez Sádaba, "Nuevas inscripciones», 87. Los autores datan la inscripción en la segunda mitad del siglo I.

119. Haynes, Blood of the Provinces, 39.

120. Saddington, The development, 57.

121. Edmondson e Hidalgo Martín ("Hallazgo», 498, n. 65) le consideran como posible veterano.

122. Le Roux y Ramírez Sádaba («Nuevas inscripciones», 88) no descartan una posible estancia de la unidad como guarnición en Hispania. Dicha cohorte habría sido reclutada en el solar peninsular.

123. Idem, 87, creen más probable la relación fraternal. 
permite pensar en una origo emeritense ${ }^{124}$. En el mausoleo que se construyó la familia de los Caecilii en Mérida descansó también Caecilia Urbana, liberta de Calventius y, probablemente, su cónyuge.

\section{Conclusiones}

Una vez analizados los epígrafes de los soldados y de los veteranos auxiliares, apuntemos algunas ideas a modo de colofón. Los núcleos familiares aparecen en una mayor cantidad de epígrafes (13, el 59\% ${ }^{125}$. Esto sucede también en los corpora epigráficos de los veteranos y de los legionarios hallados en la península ${ }^{126}$. Como ya hemos indicado, en la familia recaía generalmente la acción de conmemorar a los difuntos. Los soldados en activo aparecen mayoritariamente en las inscripciones junto a su parentela — progenitores, hermanos y cónyuges-, ya sean estos dedicantes, dedicados o, simplemente, reposen juntos. Además, estos soldados son recordados principalmente por sus familiares ( 4 epígrafes). Hay que tener en cuenta que los milites dedicados por la familia eran todos originarios del solar hispano ${ }^{127}$. También destacan las dedicaciones por parte de los heredes y commilitones (3 epígrafes). Aquí predominan soldados foráneos, como el tracio Iulius Longinus Doles o el africano Domitius, que fueron conmemorados por sus compatriotas, ya que aún no habrían creado lazos de parentesco en la península y sus familias permanecerían en su tierra natal. No debemos olvidar que algunos monumenta pudieron ser cenotafios, lo que no impide que los compañeros de armas u otra persona unida sentimentalmente o por relaciones de dependencia al miles elevaran un epígrafe funerario para este en el lugar donde se encontraba su unidad. Por otra parte, los soldados también actúan como dedicantes, tanto de epígrafes funerarios (3), fundamentalmente para sus progenitores, como de monumentos en honor de sus oficiales superiores (2).

La exigua documentación epigráfica de los veteranos auxiliares apenas permite trazar unas líneas como colofón. De los tres testimonios, dos pertenecen a los núcleos familiares, siguiendo con la preeminencia de la esfera familiar entre los soldados retirados, tal como constatamos en los

124. Wiegels, Die Tribusinschriften, 77-80.

125. La inscripción CIL, II, 5963 reforzaría esta idea si efectivamente nos encontrásemos ante un soldado auxiliar.

126. López Casado, Honesta missio, 36; López Casado, Idem in me, 33.

127. Más del $70 \%$ de los soldados raíces del estudio, es decir, que aparecen como dedicantes de otros individuos o que son sujetos de conmemoración, eran hispanos. 
veteranos legionarios de otras provincias ${ }^{128}$. Dos de ellos eran hispanos, y regresaron a su tierra natal tras la honesta missio. Aemilius Flavus llegó incluso a formar una familia.

Un dato que contrasta con el corpus de auxiliares de Britannia, así como con los corpora de veteranos y de legionarios no solo de Hispania, sino también de otras provincias, es la presencia exigua de la esposa o concubina. Tan solo hemos registrado dos mujeres en este estudio. Este hecho se explicaría por diversos factores. Uno de ellos sería el elevado grado de movilidad de estas unidades, lo que disuadiría a los soldados de formar lazos conyugales. Hasta la época flavia no se estabiliza el dispositivo militar y se integra plenamente el ejército en la estructura política y administrativa provincial, generando así una mayor constatación de este tipo de uniones, al menos entre los legionarios. Sin embargo, esto no sucede así entre los auxiliares debido a otro factor: la cronología. A nivel general, el mayor número de esposas o concubinas documentadas en la epigrafía militar tiene lugar en el siglo II y, sobre todo, en el III ${ }^{129}$. Por el contrario, el 55\% de nuestras inscripciones se fechan en la primera centuria, algunas de ellas incluso presentan una datación preflavia, época previa a la mayor expansión de la epigrafía militar funeraria en Hispania ${ }^{130}$.

Resulta inesperada la baja proporción de inscripciones de soldados auxiliares presentes en el corpus hispano en los siglos II y III, a diferencia de los veteranos y de los legionarios, sobre todo si tenemos en cuenta la mayor "romanización" de los habitantes peninsulares en virtud de la concesión del derecho latino, la urbanización, la creación de unas elites locales afines a Roma o la influencia del ejército entre otros aspectos. No obstante, a pesar del aumento del número de ciudadanos romanos incorporados a los auxilia en el siglo II, los milites de estas unidades en las provincias hispanas eran inferiores numéricamente con respecto a los legionarios. El incremento de los cives Romani en los auxilia lo percibimos incluso en esta reducida recopilación epigráfica. La primera centuria registra la mayor cantidad de una nomenclatura de un único idiónimo,

128. Los grupos de parentesco también predominan en los veteranos de provincias como Britannia o Gallia, o en los legionarios de la Galia. Sin embargo, esto no sucede en la epigrafía legionaria de Britannia.

129. Phang, The marriage, 157-159. Esto se constata en la epigrafía de los soldados auxiliares de Britannia, una provincia fuertemente militarizada, donde la presencia de la cónyuge se registra principalmente en los siglos II y, fundamentalmente, III, siendo la figura predominante en los núcleos familiares. Por el contrario, en la primera centuria predominan las relaciones ajenas al parentesco, protagonizadas por el heres, el cual encubriría casi con total certeza un compañero de armas.

130. Le Roux, «Las inscripciones», 490. 
característica de una condición peregrina de sus portadores, ya que la mayoría vivieron antes de la concesión del ius Latii — aquellos militares procedentes de núcleos que recibieron ese privilegio-; mientras que en los siglos II y III se documenta más una onomástica binominal y trinominal, acorde con la extensión de los derechos de ciudadanía. Asimismo, hay que insistir en la posibilidad de estar ante ciudadanos latinos enrolados en las unidades auxiliares, como el posible caso del jinete Sempronius Seranus.

Los equites alares son los que más monumentos epigráficos elevaron, quizá debido a los mayores emolumentos que percibían. Asimismo, también van a ser los más recordados en el momento de la muerte. El servicio en la caballería gozaba de mayor prestigio que en la infantería; prestigio con el que ya contaban los jinetes hispanos como atestiguan las fuentes literarias. No es de extrañar, por lo tanto, que la única relación de dependencia atestiguada epigráficamente sea el liberto de un eques. En la epigrafía militar hispana son los centuriones y los principales los que aparecen mayoritariamente como patroni, al igual que en otras provincias como Britannia.

Otro aspecto que destacar es el lugar de hallazgo de los monumentos epigráficos. A nivel general, tanto aquellas inscripciones que conmemoran la memoria del miles difunto, como las de los soldados que aparecen como dedicantes, independientemente de que estuvieran en la península o de que costearan el epitafio en la distancia, se localizan en núcleos urbanos de menor entidad o entornos rurales, focos de reclutamiento de soldados peregrinos $-\mathrm{O}$ latinos, pues algunos de estos centros se convertirán en municipia de promoción flavia como Caurium o Nova Augusta- Asimismo, sobresalen algunas capitales conventuales como Asturica Augusta, donde los soldados aquí hallados estarían al servicio de algún personaje destacado de la administración romana. Cabe recordar que la función del ejército romano no solo era, citando nuevamente a Le Bohec, "matar sin dejarse matar", es decir, la guerra, sino también realizaban labores de policía, de escolta o tareas administrativas. También constatamos dos epígrafes en una ciudad de mayor rango como era Augusta Emerita, capital de la provincia de Lusitania. Los auxiliares aquí documentados no tenían relación con el staff del gobernador, integrado por efectivos enviados de la Hispania Citerior al ser la Lusitania una inermis provincia, sino que eran veteranos - al menos uno con certeza-, ya que las capitales provinciales reunían una serie de condiciones políticas, económicas y sociales que las convirtieron en polos de atracción para el asentamiento de los veterani. 


\begin{tabular}{|c|c|c|c|c|c|}
\hline ONOMÁSTICA & CARGO & RELACIÓN & $\begin{array}{l}\text { LUGAR DE } \\
\text { HALLAZGGO } \\
\end{array}$ & Cronología & REFERENCIA \\
\hline $\begin{array}{l}\text { Veroblius } \\
\text { Vecif. }\end{array}$ & \begin{tabular}{|l|} 
Miles coh. III \\
Lucensium \\
\end{tabular} & $\begin{array}{l}\text { Vecius Clutami } \\
\text { f. (pater) }\end{array}$ & Lugo & S. I & CIL, II, 2584 \\
\hline $\begin{array}{l}\text { Catuenus } \\
\text { Tongif. }\end{array}$ & \begin{tabular}{|l} 
Eques alae I \\
Augustae
\end{tabular} & $\begin{array}{l}\text { Tongius Virotif. } \\
\text { (pater) }\end{array}$ & $\begin{array}{l}\text { Coria } \\
\text { (Cáceres) }\end{array}$ & $\begin{array}{l}1 .^{a} \text { mitad } \\
\text { s. I }\end{array}$ & $\begin{array}{l}\text { HEp, 12, } \\
2002,91 \\
\end{array}$ \\
\hline Longinus & $\begin{array}{l}\text { Sesquiplicarius } \\
\text { alae Vettonum } \\
\end{array}$ & $\begin{array}{l}\text { Matugenus } \\
\text { Cadanif. (?) }\end{array}$ & Ávila & $\begin{array}{l}1 .^{a} \text { mitad } \\
\text { s. I }\end{array}$ & CIL, II, 5866 \\
\hline $\begin{array}{l}\text { Capito } \\
\text { Sunnaef. }\end{array}$ & Decurio alae & $\begin{array}{l}\text { Rustica Gallif. } \\
\text { (uxor) }\end{array}$ & $\begin{array}{l}\text { Osuna } \\
\text { (Sevilla) }\end{array}$ & $\begin{array}{l}2 .{ }^{a} \text { mitad } \\
\text { S. I }\end{array}$ & $\begin{array}{c}\text { CIL, II } 2 / 5, \\
1136 \\
\end{array}$ \\
\hline $\begin{array}{l}\text { Iulius } \\
\text { Longinus } \\
\text { Doles } \\
\text { Biticentif. }\end{array}$ & $\begin{array}{l}\text { Eques alae } \\
\text { Taurianae }\end{array}$ & $\begin{array}{l}\text { Sulpicius } \\
\text { Susulla y } \\
\text { Fuscus Bithus } \\
\text { (heredes) }\end{array}$ & $\begin{array}{l}\text { Calahorra (La } \\
\text { Rioja) }\end{array}$ & $\begin{array}{l}\text { 2. }{ }^{\mathrm{a}} \text { mitad } \\
\text { S. I }\end{array}$ & CIL, II, 2984 \\
\hline $\begin{array}{l}\text { L. Marcius } \\
\text { Maternus }\end{array}$ & $\begin{array}{l}\text { Eques alae I } \\
\text { Singularium }\end{array}$ & $\begin{array}{l}\text { L. Marcius } \\
\text { Avitus (praef. } \\
\text { alae) }\end{array}$ & $\begin{array}{l}\text { Idanha- } \\
\text { a-Velha } \\
\text { (Castelo } \\
\text { Branco) } \\
\end{array}$ & $\begin{array}{l}\text { 2. }{ }^{\mathrm{a}} \text { mitad } \\
\text { s. I }\end{array}$ & $\begin{array}{l}A E, 1961 \\
\quad 358\end{array}$ \\
\hline Ignotus & Signifer & $\begin{array}{l}\text { Lapoena } \\
\text { Annonis f. } \\
\text { (mater) }\end{array}$ & $\begin{array}{l}\text { Ocaña } \\
\text { (Toledo) }\end{array}$ & $\begin{array}{l}\text { 2. }{ }^{\mathrm{a}} \text { mitad } \\
\text { s. I }\end{array}$ & IRPTo, 75 \\
\hline $\begin{array}{l}\text { Reburrus } \\
\text { Taporif. }\end{array}$ & Centurio & $\begin{array}{l}\text { Bolosea Brevif. } \\
\text { (mater) }\end{array}$ & $\begin{array}{l}\text { San Martín } \\
\text { del Castañar } \\
\text { (Salamanca) }\end{array}$ & $\begin{array}{l}\text { 2. }{ }^{\circ}-3 . \text { er } \\
\text { tercio s. I }\end{array}$ & ERPSa, 107 \\
\hline $\begin{array}{l}\text { Aemilius } \\
\text { Balaesus }\end{array}$ & \begin{tabular}{|l} 
Signifer alae \\
Sabinianae
\end{tabular} & Cognatio & $\begin{array}{l}\text { Aldeia Nova } \\
\text { (Braganza) }\end{array}$ & Fin s. I & $\begin{array}{c}\text { HEp, 7, 1997, } \\
1173 \\
\end{array}$ \\
\hline Flavos & Eques & \begin{tabular}{|l} 
Ignotus (pater) \\
y Boetela Cilif. \\
(mater)
\end{tabular} & $\begin{array}{l}\text { Granadilla } \\
\text { (Cáceres) }\end{array}$ & $\mid \begin{array}{c}\text { Fin s. I- } \\
\text { inicios s. II }\end{array}$ & $\begin{array}{c}\text { HEp, } 5,1995, \\
207\end{array}$ \\
\hline Domitius [---] & $\begin{array}{l}\text { Eques alae II } \\
\text { Flaviae }\end{array}$ & \begin{tabular}{|l|} 
C. Cornelius \\
Serenus (heres \\
et commilito)
\end{tabular} & $\begin{array}{l}\text { Astorga } \\
\text { (León) }\end{array}$ & $\mid$\begin{tabular}{c|} 
Fin s. I- \\
inicios s. II
\end{tabular} & ERPLe, 152 \\
\hline Saturninus & Miles & $\begin{array}{l}\text { Albonius Tacilli } \\
\text { f. (pater) }\end{array}$ & $\begin{array}{l}\text { S. Sebastião } \\
\text { do Freixo } \\
\text { (Leiria) }\end{array}$ & $\begin{array}{c}\text { S. I O } \\
\text { inicios s. II }\end{array}$ & CIL, II, 5230 \\
\hline $\begin{array}{l}\text { Sempronius } \\
\text { Seranus }\end{array}$ & Miles alae & $\begin{array}{l}\text { Anonyma } \\
\text { (soror) }\end{array}$ & $\begin{array}{l}\text { Lara de los } \\
\text { Infantes } \\
\text { (Burgos) } \\
\end{array}$ & S. I o II & CIL, II, 2873 \\
\hline $\begin{array}{l}\text { L. Campilius } \\
\text { Paternus }\end{array}$ & $\begin{array}{l}\text { Eques alae II } \\
\text { Flaviae }\end{array}$ & \begin{tabular}{|l} 
Flavius \\
Campilius \\
Nofirus \\
(libertus) \\
\end{tabular} & León & Inicios s. II & ERPLe, 136 \\
\hline Iulius Capito & $\begin{array}{l}\text { Miles coh. I } \\
\text { Celtiberorum o } \\
\text { I Gallicae }\end{array}$ & \begin{tabular}{|l} 
Laelius \\
Decuminus \\
(beres et \\
commilito) \\
\end{tabular} & $\begin{array}{l}\text { Luyego de } \\
\text { Somoza } \\
\text { (León) }\end{array}$ & $\begin{array}{l}\text { 1. }{ }^{\mathrm{a}} \text { mitad } \\
\text { S. II }\end{array}$ & ERPLe, 181 \\
\hline
\end{tabular}




\begin{tabular}{|l|l|l|l|c|c|}
\hline \multicolumn{1}{|c|}{ Onomástica } & \multicolumn{1}{|c|}{ CARgo } & \multicolumn{1}{c|}{ Relación } & $\begin{array}{c}\text { Lugar DE } \\
\text { Hallazgo }\end{array}$ & Cronología & Referencia \\
\hline $\begin{array}{l}\text { Publius } \\
\text { Perellius } \\
\text { Maximus }\end{array}$ & $\begin{array}{l}\text { Decurio alae II } \\
\text { Thracum }\end{array}$ & $\begin{array}{l}\text { Ignotus [--- } \\
\text { Trib. Mil. Leg.] }\end{array}$ & $\begin{array}{l}\text { San Roque } \\
\text { (Cádiz) }\end{array}$ & S. II & $\begin{array}{c}A E, 2008, \\
666\end{array}$ \\
\hline $\begin{array}{l}\text { Pentovius } \\
\text { Eleasus }\end{array}$ & Miles alae & $\begin{array}{l}\text { Elanus } \\
\text { (amicus) }\end{array}$ & $\begin{array}{l}\text { Santa Olaja } \\
\text { de la Varga } \\
\text { (León) }\end{array}$ & S. II & $\begin{array}{c}A E, 1982, \\
580\end{array}$ \\
\hline
\end{tabular}

Tabla 1. Soldados auxiliares en activo

\begin{tabular}{|c|c|c|c|c|c|}
\hline ONOMÁSTICA & CARGO & RELACIÓN & $\begin{array}{l}\text { LUGAR DE } \\
\text { HALLAZGO } \\
\end{array}$ & Cronología & REFERENCIA \\
\hline $\begin{array}{l}\text { Toncius } \\
\text { Toncetamif. }\end{array}$ & $\begin{array}{l}\text { Veter. Coh. II } \\
\text { Lusitanorum }\end{array}$ & $\begin{array}{l}\text { Ardunnus } \\
\text { Cominif. (?) }\end{array}$ & $\begin{array}{l}\text { Fundão } \\
\text { (Castelo } \\
\text { Branco) }\end{array}$ & $\begin{array}{l}\text { 1. }{ }^{\mathrm{a}} \text { mitad } \\
\mathrm{s} . \mathrm{I}\end{array}$ & $E E$, VIII, 14 \\
\hline $\begin{array}{l}\text { Aemilius } \\
\text { Flavus }\end{array}$ & Missicius & $\begin{array}{l}\text { Saturninus } \\
\text { (filius) }\end{array}$ & $\begin{array}{l}\text { Perales } \\
\text { de Milla } \\
\text { (Madrid) }\end{array}$ & S. II & ILCAM, 90 \\
\hline Ignotus & Veter alae & Ignota (uxor) & $\begin{array}{l}\text { Mérida } \\
\text { (Badajoz) }\end{array}$ & $\begin{array}{c}\text { Fin s. II- } \\
\text { inicios s. } \\
\text { III }\end{array}$ & $\begin{array}{l}\text { HEp, 18, } \\
2009,32\end{array}$ \\
\hline
\end{tabular}

Tabla 2. Veteranos auxiliares

\begin{tabular}{|c|c|c|c|c|c|}
\hline ONOMÁSTICA & CARGO & RELACIÓN & $\begin{array}{l}\text { LUGAR DE } \\
\text { HALLAZGO }\end{array}$ & Cronología & REFERENCIA \\
\hline Ignotus & $\begin{array}{l}\text { [--- eques] alae } \\
\text { II Thracum }\end{array}$ & Arro (frater) & $\begin{array}{l}\text { Villalcampo } \\
\text { (Zamora) }\end{array}$ & \begin{tabular}{|c|} 
Mediados \\
I
\end{tabular} & CIRPZa, 240 \\
\hline $\begin{array}{l}\text { Q. Caecilius } \\
\text { Q.f. Pap. } \\
\text { Varica }\end{array}$ & $\begin{array}{l}\text { ? Cohors } \\
\text { Antistiana }\end{array}$ & $\begin{array}{l}\text { Q. Caecilius } \\
\text { Q.f. Pap. } \\
\text { Calventius } \\
\text { (frater) }\end{array}$ & $\begin{array}{l}\text { Mérida } \\
\text { (Badajoz) }\end{array}$ & $\begin{array}{l}2 .^{\mathrm{a}} \text { mitad } \\
\text { s. I }\end{array}$ & $\begin{array}{c}A E, 1993, \\
915\end{array}$ \\
\hline
\end{tabular}

Tabla 3. Auxiliares incerti

\section{FuENTES CLÁSICAS}

Gayo: Institutes. Texte établi et traduit par Julien Reinach. Paris: Les Belles Lettres, 1950.

Tácito: Historiae. 3 vols. Texte établi et traduit par Eugène de Saint-Denis. Paris: Les Belles Lettres, 1987-1992.

Tácito: Vie d'Agricola. Texte établi et traduit par Eugène de Saint-Denis. Paris: Les Belles Lettres, 1972. 
6. Bibliografía

Alföldy, Géza. "Neue und revidierte Militarinschriften aus dem romischen Hispanien. 2. Eine Reiter der ala Vettonum». En Römische Heeresgeschichte. Beiträge 1962-1985 (Mavors 3), editado por Géza Alföldy, 514-519. Amsterdam: J. C. Gieben, 1987.

Alföldy, Géza. "Ein Prokurator aus Carteia». Habis 43 (2012): 165-175.

Abascal Palazón, Juan Manuel. Los nombres personales en las inscripciones latinas de Hispania. Murcia: Universidad de Murcia, 1994.

Abascal Palazón, Juan Manuel. «Oficinas y estilos en el hábito epigráfico de la Hispania romana». En Artífices idóneos: Artesanos, talleres y manufacturas en Hispania, editado por Macarena Bustamante-Álvarez y Darío Bernal Casasola, 143-168. Mérida: CSIC, 2014.

Abascal Palazón, Juan Manuel y Géza Alföldy. Inscripciones romanas de la provincia de Toledo (siglos I-III) (IRPTo). Madrid: Real Academia de la Historia, 2015.

Abásolo Álvarez, José Antonio. "Las estelas decoradas de la región de Lara de los Infantes: estudio iconográfico». BSAA 43 (1977): 61-97.

Abásolo Álvarez, José Antonio. "Sobre algunas escuelas hispanorromanas». BSAA 60 (1994): 187-224.

Alonso Ávila, M. ${ }^{a}$ Ángeles y Santos Crespo Ortiz de Zárate. Corpus de inscripciones romanas de la provincia de Burgos: fuentes epigráficas para la historia social de Hispania romana (CIRPBu). Valladolid, 2000.

Alonso Ávila, M. ${ }^{\mathrm{a}}$ Ángeles y Santos Crespo Ortiz de Zárate. Corpus de inscripciones romanas de la provincia de Zamora: fuentes epigráficas para la bistoria social de Hispania romana (CIRPZa). Valladolid, 2000.

Andreu Pintado, Javier. «Latinización y municipalización en el Alto Imperio: nuevas perspectivas para el estudio de la Hispania de los Flavios». En Antiqua Iuniora: en torno al Mediterráneo en la Antigüedad, coordinado por Francisco Beltrán Lloris, 189-210. Zaragoza: Universidad de Zaragoza, 2004.

Benseddik, Nacéra. Les troupes auxiliaires de l'armée romaine en Maurétanie Césarienne sous le Haut-Empire. Alger: Société nationale d'édition et de difusión, 1979.

Breeze, David J. "Pay Grades and Ranks below the Centurionate». JRS LXI (1971): 130-135.

Brizzi, Giovanni. "Socii et auxilia". En Les auxiliaires de l'armée romaine. Des alliés aux fédérés. Actes du sixième Congrès de Lyon (23-25 octobre 2014), editado por Catherine Wolff y Patrice Faure, 37-51. Lyon: CEROR, 2016. 
Caballos Rufino, Antonio. El nuevo bronce de Osuna y la política colonizadora romana. Sevilla: Universidad de Sevilla, 2006.

Campbell, Brian. "The marriage of Soldiers under the Empire». JRS LXVIII (1978): 153-166.

Cebrián Fernández, Rosario. Titvlvm fecit: la producción epigráfica romana en las tierras valencianas. Madrid: Real Academia de la Historia, 2000.

Cheesman, George L. The Auxilia of the Roman Imperial Army. Oxford: Clarendon Press, 1914.

Christol, Michel y Patrick Le Roux. "L'aile Tauriana Torquata et les relations militaires de l'Hispania et de la Maurétanie tingitane entre Claude et Domitien». AntAfr 21, 1 (1985): 15-33.

Costa García, José Manuel. "Tras los pasos de la cohors I Celtiberorum: evidencias arqueológicas». BSAA 75 (2009): 201-222.

Curchin, Leonard A. "Roman Army Recruitment in Central Spain: An Untapped Archive from the District of Laraw. The Ancient World 26 (1995): 51-58.

Dana, Dan. «'impact de l'onomastique latine sur les onomastiques indigènes dans l'espace thrace». En Les noms des personnes dans l'Empire romain, editado por Monique Dondin-Payre, 37-87. Bordeaux: Ausonius, 2011.

Dana, Dan. Onomasticon Thracicum. Répertoire des noms indigènes de Thrace, Macédoine Orientale, Mésies, Dacie et Bithynie. Athína: De Boccard, 2014.

Eck, Werner. «Der Einschluss der Kinder in kaiserliche Bürgerrechtskonstitutionen nach der Reform des Antoninus Pius im Jahr 140: Einblicke in die römische Administration». En People and Institutions in the Roman Empire. Essays in Memory of Garrett G. Fagan, editado por Andrea F. Gatzke, Lee L. Brice y Matthew Trundle, 68-82. Leiden/Boston: Brill, 2020.

Edmondson, Jonathan y Luis Ángel Hidalgo Martín. «Hallazgo de dos epitafios de "veterani» en Mérida. Vidas paralelas de dos soldados "Augustani" (emeritenses) a finales del siglo I d.C.». Mérida. Excavaciones arqueológicas 10 (2004): 479-507.

Gómez-Pantoja, Joaquín. «Miles ale F(---)». ZPE 191 (2014): 282-284.

González Herrero, Marta. "Catuenus, Tongif., miles eques perteneciente al ala primera Augusta». Emerita LXXXVIII 2 (2020): 325-337.

González Rodríguez, M. ${ }^{a}$ Cruz. Las unidades organizativas indígenas del área indoeuropea de Hispania. Vitoria-Gasteiz: Instituto de Ciencias de la Antigüedad, 1986. 
González Rodríguez, M. ${ }^{a}$ Cruz y Manuel Ramírez Sánchez. «Unidades organizativas indígenas del área indoeuropea de Hispania III: Addenda». Veleia 28 (2011): 253-267.

Greene, Elisabeth M. «Conubium cum uxoribus: wives and children in the Roman military diplomas». JRA 28 (2015): 125-159.

Haynes, Ian. Blood of the Provinces. The Roman Auxilia and the Making of Provincial Society from Augustus to the Severans. Oxford: Oxford University Press, 2013.

Hernández Guerra, Liborio. Epigrafía romana de la provincia de Salamanca (ERPSa). Valladolid: Universidad de Valladolid, 2001.

Hernando Sobrino, M. ${ }^{a}$ del Rosario. "A propósito de CIL II 5866 (Ávila): Un epígrafe recuperado, aumentado y corregido». AEspA 87 (2014): 273-286.

Holder, Paul A. Studies in the Auxilia of the Roman Army from Augustus to Trajan. Oxford: BAR, 1980.

Holder, Paul A. The Roman Army in Britain. London: Batsford, 1982.

Jiménez de Furundarena, Agustín. «Historia y prosopografía del Ala II Flavia hispanorum civium romanorum». HAnt XXII (1998): 203-232.

Jiménez de Furundarena, Agustín. «Historia y prosopografía de la cohors I Celtiberorum civium romanorum». HAnt XXVI (2002): 99-120.

Jiménez de Furundarena, Agustín. «Historia y prosopografía de la cohors I Gallica equitata civium romanorum». Aquila Legionis 9 (2007): 77-107.

Jordán Lorenzo, Ángel. «Precisiones a un altar votivo de Poza de la Sal: un eques de la legio VI Victrix. HAnt XXXV (2011): 261-270.

Kraft, Konrad. Zur Rekrutierung der Alen und Kohorten au Rhein und Donau. Bern: A. Francke, 1951.

Le Bohec, Yann. El ejército romano: instrumento para la conquista de un imperio. Barcelona: Ariel, 2004.

Le Bohec, Yann. «Sur les auxiliaires de l'armée romaine: des alliés aux fédérés". En Les auxiliaires de l'armée romaine. Des alliés aux fédérés. Actes du sixième Congrès de Lyon (23-25 octobre 2014), editado por Catherine Wolffy Patrice Faure, 23-33. Lyon: CEROR, 2016.

Le Roux, Patrick. L'armée romaine et l'organisation des provinces ibériques d'Auguste à l'invasion de 409. Paris: De Boccard, 1982.

Le Roux, Patrick. "Las inscripciones militares». En El ejército romano en Hispania. Guía arqueológica, editado por Ángel Morillo Cerdán, 481501. León: Universidad de León, 2007.

Le Roux, Patrick. "Duplicarius, duplarius, sesquiplicarius: un réexamen». En Le métier de soldat dans le monde romain. Actes du cinquième congrès de Lyon, 23-25 septembre 2010, editado por Catherine Wolff, 523532. Lyon: Centre d'Études Romaines, 2012. 
Le Roux, Patrick y José Luis Ramírez Sádaba. "Nuevas inscripciones funerarias de Mérida». Anas 6 (1993): 85-93.

Le Roux, Patrick y José Luis Ramírez Sádaba. "Un nuevo testimonio del Ala Miliaria de Mauretania Caesariensis en Augusta Emerita de Lusitania». En Espacios, usos y formas de la epigrafía bispana en épocas antigua y tardoantigua: homenaje al Dr. Armin U. Stylow. Anejos de Archivo Español de Arqueología XLVIII, 297-306. Madrid: CSIC, 2009.

Leite de Vasconcelos, José. "Aula de Numismatica de Biblioteca Nacional de Lisboa». O Arqueólogo Português VII (1902): 161-172.

López Casado, Roberto. Honesta missio. Los veteranos en las sociedades provinciales del Imperio Romano occidental a través de la epigrafía. Valladolid: Universidad de Valladolid, 2018.

López Casado, Roberto. Idem in me. Legión, familia y sociedad en el occidente romano. Salamanca: Universidad de Salamanca, 2021.

Lörincz, Barnabas, ed. Onomasticon Provinciarum Europae Latinarum, vol. II: Cabalicius-Ixus (OPEL, II). Wien: Forchungsgesellschaft Wiener Stadtarchäologie, 1999.

Mann, John C. Legionary Recruitment and Veterans Settlement during the Principate. London: Institute of Archaeology Occasional, 1983.

Martino García, David. "Acerca de la cronología de la epigrafía Vadiniense. Revisión historiográfica y nuevas propuestas». ETF II, 25 (2012): 305326.

Maxfield, Valerie A. The military decorations of the Roman army. London: Batsford, 1981.

Meyer, Alexander. The creation, composition, service and settlement of Roman auxiliary units raised on the Iberian Peninsula. Dissertation: Duke University, 2012. https://dukespace.lib.duke.edu/dspace/ handle/10161/5566 [consultado el 12/9/2020].

Meyer, Elizabeth A. «Explaining the epigraphic habit in the Roman Empire: the evidence of epitaphs". JRS LXXX (1990): 74-96.

Mongelli, Francesco. "Il matrimonio dei militari romani e il lemma Suid 181 Adler». Politica Antica IX (2019): 171-193.

Palao Vicente, Juan José. "Presencia militar romana en la actual provincia de Zamora". Brigecio 9 (1999): 45-56.

Palao Vicente, Juan José. Legio VII Gemina (Pia) Felix: estudio de una Legión romana. Salamanca: Universidad de Salamanca, 2006.

Palao Vicente, Juan José. "Las tropas auxiliares del exercitus Hispanicus». REA 112, 1 (2010): 169-189.

Palao Vicente, Juan José. "Lejos de casa. Destinos, traslados, viajes y retiros del soldado romano durante el Alto Imperio". En Viajes y cambios de residencia en el mundo romano, editado por Iglesias Gil, José Manuel 
y Alicia Ruiz Gutiérrez, 177-200. Santander: Universidad de Cantabria, 2011.

Palao Vicente, Juan José. "Reburus Tapori f., un centurión auxiliar olvidado". Ephemeris Napocensis XXV (2015): 167-175.

Pavkovič, Michael F. The legionary horsemen: an essay on the equites legionis and equites promoti. Dissertation: University of Hawaii, 1991. https://scholarspace.manoa.hawaii.edu/handle/10125/9885 [consultado el 6/10/2020].

Perea Yébenes, Sabino. «Notas sobre la epigrafía militar en Clunia». HAnt XV (1991): 193-206.

Perea Yébenes, Sabino. "Los diplomas militares, documentos singulares para la integración jurídica y social de los soldados peregrini al servicio de Roma. Una introducción a su estudio». En Formas de integración en el mundo romano, editado por Gonzalo Bravo y Raúl González Salinero, 97-118. Madrid: Signifer, 2009.

Phang, Sara E. The marriage of Roman soldiers (13 B.C.-A.D. 235): law and family in the imperial army. Leiden/Boston/Köln: Brill, 2001.

Pitillas Salañer, Eduardo. "La figura del compañero de armas en la epigrafía funeraria romana del NW de Hispania. Una aproximación». HAnt XXXII (2008): 143-154.

Rabanal Alonso, Manuel A. y Sonia García Martínez. Epigrafía romana de la provincia de León: revisión y actualización (ERPLe). León: Universidad de León, 2001.

Roldán Hervás, José Manuel. Hispania y el ejército romano. Contribución a la historia social de la España antigua. Salamanca: Universidad de Salamanca, 1974.

Roxan, Margaret M. The auxilia of the Roman Army raised in the Iberian Peninsula. Doctoral Thesis: London University, 1973. https://discovery. ucl.ac.uk/id/eprint/1318033/ [consultado el 26/9/2020]

Royo Martínez, María del Mar. "Onomástica y sociedad en la epigrafía latina antigua de la Comunidad Autónoma de Madrid». ETF II, 23 (2010): 369-394.

Ruiz Trapero, María. Inscripciones latinas de la Comunidad de Madrid (siglos I-VIII), Madrid (ILCAM). Madrid: Consejería de Educación, 2001.

Saddington, Dennis B. The development of the Roman auxiliary forces from Caesar to Vespasian (49 a.C.-79 d. C.). Harare: University of Zimbabwe, 1982.

Salas Martín, José y Antonio González Cordero. «Nuevas aportaciones a la epigrafía latina de la provincia de Cáceres». Norba. Revista de Historia 11-12 (1991-1992): 173-200. 
Saller, Richard. P. y Brent D. Shaw. "Tombstones and family relations in the Principate: civilians, soldiers and slaves». JRS LXXIV (1984): 124-156.

San Vicente González de Aspuru, José Ignacio. "Galba, el ala Tauriana y el ala Sulpicia». HAnt XXXI (2007): 87-110.

Santos Yanguas, Narciso. El ejército y la romanización de Galicia: conquista y anexión del noroeste de la Península Ibérica. Oviedo: Universidad de Oviedo, 1988.

Santos Yanguas, Narciso. «Oficiales astures en las tropas auxiliares romanas». HAnt XXXIII-XXXIV (2009-2010): 111-130.

Santos Yanguas, Narciso. "Soldados astures en las tropas auxiliares romanas». Tiempo y Sociedad 24 (2016): 7-55.

Seeck, Otto. Notitia dignitatum: Accedunt, notitia urbis Constantinopolitanae et tabercula provinciarum. Frankfurt: Minerva, 1962 (1. ${ }^{\mathrm{a}}$ ed. 1876).

Spaul, John E. Ala2: the auxiliary cavalry units of the pre-Diocletianic imperial Roman army. Andover: Nectoreca Press, 1994.

Spaul, John E. Cohors2: the evidence for and a short bistory of the auxiliary infantry units of the Imperial Roman Army. Oxford: Archaeopress, 2000.

Speidel, Michael A. "Roman army pay scales revisited: responses and answers». En De l'or pour les braves! : Soldes, armées et circulation monétaire dans le monde romain, editado por Michael Reddé, 53-62. Bordeaux: Ausonius, 2014.

Speidel, Michael A. "Actium, Allies, and the Augustan Auxilia: reconsidering the transformation of military structures and foreign relations in the reign of Augustus». En Les auxiliaires de l'armée romaine. Des alliés aux fédérés. Actes du sixième Congrès de Lyon (23-25 octobre 2014), editado por Catherine Wolff y Patrice Faure, 79-95. Lyon: CEROR, 2016.

Vallejo Ruiz, José María. Antroponimia indigena de la Lusitania romana. Vitoria-Gasteiz: Universidad del País Vasco, 2005.

Waebens, Sofie. "Imperial Policy and Changed Composition of the Auxilia: The "Change in A.D. 140» Revisited». Chiron 42 (2012): 1-23.

Watson, George R. The Roman Soldier. London: Thames and Hudson, 1969.

Webster, Graham. The Roman Imperial Army of the First and Second Centuries A.D. London: Adam and Charles Black, 1969.

Wiegels, Rainer. Die Tribusinschriften des römischen Hispanien. Ein Katalog. Berlin: Walter de Gruyter \& Co., 1985. 